\title{
A politização das conversas cotidianas e suas relações com processos deliberativos ${ }^{1}$
}

\section{Ângela Cristina Salgueiro Marques e Luís Mauro Sá Martino}

\section{Resumo}

A tradição deliberativa nos estudos de Comunicação

e Política destaca frequentemente a ação da

conversação cívica como uma das bases da

democracia. No entanto, menos atenção é dada às

conversas triviais, descartadas do ponto de sua

possível contribuição política à reflexão acerca de

problemas coletivos. Este texto, a partir de pesquisa

bibliográfica, busca resgatar os sentidos políticos do

trivial destacando as possibilidades de politização

das falas cotidianas. 0 argumento se desenvolve em

três momentos: (1) diferenciando a deliberação da

conversação, (2) destacando os aspectos políticos

desta última, (3) com especial menção à produção de

narrativas de si nesse processo. A partir disso, avança-

se a hipótese de que as conversações cotidianas,

longe de qualquer trivialidade, se apresentam como

processos fundamentais para a formação de uma

opinião pública política.

\section{Palavras-Chave}

Democracia. Deliberação. Identidade.

Política. Comunicação.

\section{Ângela Cristina Salgueiro Marques ।}

angelasalgueiro@gmail.com

Doutora pelo Programa de Pós-Graduação em Comunicação Social da Universidade Federal de Minas Gerais - UFMG, Brasil. Professora do PPGCOM da UFMG.

\section{Luís Mauro Sá Martino I Imsamartino@gmail.com}

Doutor em Ciências Sociais pela Pontifícia Universidade Católica de São Paulo - PUC-SP, Brasil. Professor do Programa de Pós-Graduação em Comunicação da Faculdade Cásper Líbero, Brasil.

\section{Introdução}

As conversações cotidianas sobre a política são frequentemente iniciadas nos contextos comunicativos informais. Em virtude de seu caráter prosaico, fluido e descontínuo, elas costumam ser, de antemão, descartadas enquanto discursos capazes de prover contribuições ao processo político. Acreditamos, todavia, que elas surgem como fonte geradora da opinião pública e do entendimento de questões ligadas tanto ao cotidiano, quanto ao sistema político e administrativo. É preciso considerar, assim, que as possíveis contribuições que a conversação cotidiana informal pode oferecer ao processo deliberativo dependem intrinsecamente de sua abertura ao conflito. A exposição a visões conflitantes é um elemento central para a discussão política e para a construção da autonomia dos cidadãos (BENHABIB, 1996; HABERMAS, 1997; FEARON, 1998).

Os cidadãos constroem, cotidianamente, contextos comunicativos nos quais conversam e discutem a respeito de seus problemas e suas necessidades. 
Nesses contextos relacionais do cotidiano, a conversação é fundamental para a constituição de quadros compartilhados de referência para o entendimento das principais questões que os afetam. Não só problemas individuais são enunciados e discutidos, como também questões mais gerais, que fazem referências a valores e procedimentos. De modo geral, as conversações políticas ordinárias são constituídas por uma mistura entre questões políticas, eventos mais prosaicos e experiências pessoais, aproximando as dimensões do público e do privado (WYATT, KATZ e KIM, 2000; HERBST, 1996; DAHLGREN, 2003b, 2009; GAMSON, 1992).

A democracia requer um escopo ampliado de espaços e contextos comunicativos nos quais os cidadãos possam articular seus enunciados e empreender conversações e discussões sobre os assuntos que os concernem, desenvolvendo suas capacidades de argumentação, reflexão e domínio cognitivo sobre diferentes tipos de informações (CALHOUN, 1992; HABERMAS, 1997; BURKHALTER et al., 2002; DAHLBERG, 2005). No entanto, muitos pesquisadores ressaltam a pouca atenção teórica conferida à conversação em situações cotidianas e aos modos como os cidadãos constituem seus contextos rotineiros de reflexão e discussão sobre problemas públicos (ELIASOPH, 1996, 1997; HERBST, 1996; SCHEIN, 1995; MOY e GASTIL, 2006).
Para Eliasoph (1999, 2000), as conversações distantes do espaço de visibilidade ampliada, apesar de pouco exploradas e investigadas, podem revelar como os cidadãos comuns, ao interagirem cotidianamente com os outros, desenvolvem capacidades políticas para pensar além de seus interesses particulares, aprimorando alternativas de participação política. Além disso, são as cenas de interpelação e enunciação criadas no cotidiano que favorecem o questionamento e a redefinição de enquadramentos e de valores que configuram percepções, julgamentos e avaliações do mundo, dos outros e das mais diversas formas de poder e opressão. Essas conversações acontecem nos espaços menos visíveis das relações pessoais, das interpelações casuais e dos encontros cotidianos, nos quais, sotto voce, também existe uma perspectiva política: 0 que não pode ser dito na visibilidade do espaço público pode encontrar guarida nessas conversas que, mesmo longe do "público", se mostram eficazes na construção de opiniões de dissenso. Estamos próximos do que Scott (2008) denomina "códigos ocultos" (hidden transcripts), formas de resistência que, longe dos circuitos discursivos principais, elaboravam sua própria trama enunciativa.

Nesse sentido, um tipo de cidadania construída dia a dia, através das práticas comunicativas, parece revelar como os cidadãos constituemse - ainda que diante de inúmeras assimetrias

Uma primeira versão do texto foi apresentada no $10^{\circ}$ Encontro da Associação Brasileira de Ciência Política (ABCP), ocorrido entre 30/8/2016 e 2/9/2016 na cidade de Belo Horizonte. Agradecemos ao apoio do CNPq e da Fapemig, que financiam 0 projeto do qual esse texto é resultado. 
e desigualdades - como autores autônomos de suas próprias vidas, assumindo responsabilidade por suas próprias decisões e desenvolvendo a habilidade de justificá-las diante dos outros.

Sob esse aspecto, as conversações são fundamentais para a criação de modos mais complexos de entendimento de situações, políticas públicas, programas ou questões problemáticas relativas à vida coletiva dos cidadãos (GAMSON, 1992; MANSBRIDGE, 1999; SCHEUFELE, 2000; CONOVER et al, 2002; ALDÉ, 2001, MARQUES e MAIA, 2007, 2010; MARQUES e ROCHA, 2007).

Como alguns autores já apontaram (BOHMAN, 1996; PORTO, 1998; MAIA, 2004; NORRIS, 2000), 0 dilema democrático não se resume à posse de informações, mas estende-se a processos de construção discursiva do conhecimento, em que os participantes devem demonstrar capacidades comunicativas para engajar-se na troca argumentativa com outras pessoas ou outros grupos sociais que apresentam opiniões ou crenças divergentes. Nessas trocas, o que está em jogo também é a disputa pela construção e definição de enquadramentos, os quais servem tanto para organizar os elementos discursivos que constituem o problema em pauta, quanto para definir os termos de seu entendimento coletivo e, assim, da negociação e busca por soluções. 0 enquadramento não só "nomeia" um problema público, como participa ativamente de sua construção, ao criar certas associações e não outras entre conceitos centrais de uma dada questão. Nesse processo, os enquadramentos passam a agrupar, e mesmo a representar, demandas, discursos, narrativas e argumentos (GAMSON, 1992).

Através das conversações cívicas e da constante redefinição de enquadramentos, grupos e indivíduos podem exercer poder, determinar formas de controle e questionar legitimidades e hegemonias tidas como dadas. Grupos minoritários podem, por exemplo, identificar injustiças, elaborar e desafiar simbolicamente desigualdades, orientar a construção de seu autoentendimento, sinalizar possíveis rotas de interpretação de seus problemas e construir narrativas compartilhadas que se opõem àquelas que os mantêm na condição opressora de "subalternos" (YOUNG, 1990; MARQUES e MAIA, 2010).

Dito de modo breve, a conversação informal é constituída, em um primeiro momento, pelo prazer de estar junto, de compartilhar com 0 outro os momentos vividos, sem a preocupação de atingir metas e objetivos a curto ou longo prazo. Ela privilegia os processos de construção da empatia entre os interlocutores, auxiliando-os a organizar e entender as demandas práticas de sua existência, questionando hierarquias, preconceitos e formas de subordinação (KIM e KIM, 2008; MARQUES e MAIA, 2008, 2010). Essa perspectiva é explorada neste trabalho. 0 argumento se desenrola em três etapas. 
Em primeiro lugar, serão delineadas algumas diferenças entre "conversação" e "deliberação", sugerindo que a primeira se refere às interações gerais, enquanto a última está vinculada a momentos e práticas específicas. Na sequência, são destacados os aspectos políticos - para além da deliberação - das conversações cotidianas, reservando-se especial atenção ao aspecto argumentativo que as narrativas de si possuem nesse contexto. A hipótese avançada é a de que as conversas cotidianas, para além de qualquer trivialidade, são espaços importantes para a formação de uma opinião pública política.

\section{A conversação no processo deliberativo}

Vários autores evidenciam as diferenças existentes entre os papéis desempenhados pela conversação cívica cotidiana e pela discussão ou deliberação política no processamento de questões de interesse ou relevância pública (FEARON, 1998; BURKHALTER et al., 2002; SANDERS, 1997; MOY e GASTIL, 2006).

Sabemos que, em um processo deliberativo ampliado (articulando várias esferas públicas de discussão), as dinâmicas comunicativas tendem a se dar de forma integrada, mas nem sempre coordenada e simultânea.

Autores como McLeod et al. (1999) e Bohman (2007) parecem compartilhar desse mesmo ponto de vista quando afirmam que a conversação, por ter um caráter primordialmente privado (reunindo pessoas com afinidade de perspectivas) e por não exigir um intenso cuidado e consideração das razões a favor de e contra uma determinada proposição, não ofereceria as condições de inclusividade e publicidade requeridas por uma deliberação voltada para a solução de problemas coletivos. Por sua vez, Gutmann e Thompson (1999) ressaltam que o tipo de conversação válida para a deliberação é aquela "intencionalmente dirigida para questões que o público deva discutir e possivelmente agir sobre" (1999, p. 274).

Também Habermas (1987), ao estabelecer dois níveis distintos de práticas discursivas, aponta para uma diferença entre conversação e deliberação. Um primeiro nível comporta o que ele chama de "prática comunicativa ingênua", 0 qual apresenta um grau de problematização implícito ou latente. Um segundo nível corresponderia ao uso reflexivo da linguagem, ou ao discurso orientado para a busca de um entendimento mútuo e para a ação prática efetiva. Habermas caracteriza a inter-relação existente entre esses dois níveis conferindo grande importância às conversações estabelecidas em contextos rotineiros de descoberta de problemas comuns, de interpretação de necessidades e de construção conjunta de entendimentos. Mas, para ele, a real dificuldade está na passagem de um nível ao outro - onde se coloca o papel da esfera pública em prover mediações e conexões entre diferentes arenas e modos de comunicação - e não em identificar qual deles produz, com maior eficácia, ganhos democráticos, descartando automaticamente 0 outro. 
Independentemente dessas distinções, a conversação cívica, construída em contextos informais de convivência, apresenta uma importância social ligada ao estabelecimento de vínculos associativos, de solidariedade, de compartilhamento e de pertencimento. Ela é responsável pela criação de redes de sociabilidade que permitem aos sujeitos e grupos expressarem seus dilemas, anseios e necessidades, oferecendolhes oportunidades de trabalhar e expor seus enunciados em cenas expressivas, nas quais é possível desenvolver capacidades comunicativas, políticas e relacionais. É na conversação cotidiana que experimentamos e colocamos à prova os modos como nossos gestos simbólicos (Mead) e nossas performances linguageiras afetam os outros (ações reciprocamente referenciadas) e neles produzem todo um movimento em direção à interlocução e à resposta (seja em atendimento a determinadas expectativas, seja não correspondendo a elas e promovendo rupturas e até mesmo o que consideramos como incivilidades).

É nesse sentido que Mansbridge (1999) afirma que a conversação cotidiana produz resultados democraticamente válidos através de efeitos combinados e interativos de ações de indivíduos relativamente isolados. Em contrapartida, a deliberação pode ocorrer em uma assembleia de tomada de decisão, onde os resultados geralmente são obtidos por meio da troca de razões. Segundo ela, determinadas conversações sociáveis podem desafiar preconceitos e regras estigmatizantes, ao deslocar experiências negativas de contextos privados para espaços coletivos de debate, em que as pessoas compartilham informações e constroem conjuntamente o conhecimento. Por exemplo, experiências de violência doméstica, homofobia, machismo ou preconceito racial, ao se transformarem em tópico principal de uma conversação, podem ajudar na contestação de regras ou discursos tidos como não problemáticos ou incontestáveis (MAIA e MARQUES, 2002).

A relevância política das questões não é determinada, contudo, pelo tipo de arena na qual elas são tematizadas ou pelo tempo dedicado à sua discussão (considerando-se também 0 tempo de fala de cada ator), apesar de esses serem fatores importantes. Nem tampouco o envolvimento político dos cidadãos comuns pode ser imposto pelo contexto no qual eles atuam ou deveriam atuar. Nem todos os problemas podem ser solucionados com uma maior maximização de tempo ou concentração reflexiva dos participantes reunidos em contextos excepcionais de deliberação.

Argumentamos, assim, que é mais profícuo pensar em uma complementaridade entre as conversações sociáveis e as discussões e deliberações políticas do que em uma maneira de eleger qual delas pode ser apontada como a fonte dos conflitos que se estruturam em e constituem diferentes esferas públicas. Partimos do pressuposto de que 0 processo deliberativo é formado pela interconexão entre contextos comunicativos plurais, os 
quais reúnem vários atores e seus modos de comunicação específicos; e de que a deliberação é uma atividade que envolve 0 enfrentamento público dos discursos resultantes desses múltiplos contextos.

Aqui nos aproximamos da proposta de Jane Mansbridge (1999) de pensar a deliberação como integração de diferentes práticas e momentos comunicativos que se conectam de maneira a configurar uma rede complexa que se molda na articulação e desarticulação de partes que se interceptam e tendem a interferir umas nas outras. Assim, ela pensa a atividade deliberativa operando como um "sistema" através da articulação de dinâmicas comunicacionais que se processam em espaços de discussão e conversação os mais diversos:

0 que denomino sistema deliberativo resulta da conversação entre representantes formais e informais em fóruns públicos designados, da conversação entre constituintes e representantes eleitos ou outros representantes de organizações orientadas politicamente, da conversação na mídia, da conversação entre ativistas políticos, e da conversação cotidiana em espaços privados sobre coisas que o público deveria discutir - todos fazendo parte do que chamo de sistema deliberativo" (1999, p. 211).

Mansbridge assume que, ao utilizar a palavra "sistema", não pretende "sugerir que as partes de um todo possuem entre si uma relação mecânica ou perfeitamente previsível, embora ambos esses atributos sejam conotações das palavras 'sistema' e ‘sistemático' no discurso ordinário”. Ao invés disso, ela busca sugerir uma "inter-relação entre as partes, de modo que uma mudança em uma delas tende a afetar as outras" (1999, p. 228).

É importante ter cuidado com o pressuposto da mútua afetação e influência entre esferas ou âmbitos comunicativos que integram o processo deliberativo, pois nem sempre eles se tangenciam, nem sempre sua articulação produz resultados democráticos e, na maior parte das vezes, se ignoram reciprocamente.

Também Habermas apresentou recentemente uma concepção sistêmica das trocas comunicativas em redes de esferas públicas ao afirmar que:

A comunicação política, circulando de baixo para cima e de cima para baixo através de um sistema de múltiplos níveis (desde a conversação cotidiana na sociedade civil, passando pelo discurso público e pela comunicação mediada até os discursos institucionalizados no centro do sistema político), assume formas bastante distintas em diferentes arenas do sistema político" (Habermas, 2006, p. 415).

Todavia, em Habermas, a conversação cívica cotidiana possui um grau de ingenuidade e ineficácia política para intervir nas ações do poder administrativo. Para alguns autores (MOY e GASTIL, 2006; MUTZ e MONDAK, 2006; DUCHESNE e HAEGEL, 2004b, 2006; GAMSON, 1992; PORTO, 2001, 2003b), para que a conversação cívica proporcione 0 desenvolvimento de capacidades políticas e deliberativas, é necessário que os interlocutores estejam situados em redes informais de 
conversação cotidiana perpassadas pela deliberação mediada, a qual reúne uma diversidade de posições e argumentos. Assim, o uso das informações midiáticas, associado à discussão interpessoal, possibilitaria aos participantes meios de tornar seus argumentos mais compreensíveis, facilitando também a interpretação das perspectivas alheias, na construção conjunta de entendimentos sobre 0 universo ampliado da política.

Como destacam Kim e Kim, apesar de serem triviais e de geralmente não possuírem objetivos específicos (no que tange à realização de ações práticas), as conversações do cotidiano proporcionam interlocuções nas quais os cidadãos "interagem livremente para entender a si mesmos e aos outros, resultando na produção e reprodução de regras, valores partilhados, razões públicas” (2008, p. 53). A conversação cívica cotidiana favorece, portanto, "oportunidades de pensar sobre as próprias idéias, de reduzir sua inconsistência cognitiva aumentando a qualidade das opiniões e argumentos individuais" (KIM e KIM, 2008, p. 61). Mas, para fazer tudo isso, a conversação precisa se politizar.

Graham (2008) ressalta a importância da observação de conversações que abrangem temas da vida pessoal e coletiva do cotidiano, nas quais um ou mais participantes, ao conferirem atenção a um tema ou tópico que acreditam merecedor de atenção e discussão pública, tendem a tornar possível a emergência de uma discussão política.
De modo geral, muitos são os pesquisadores que afirmam que pouca atenção teórica tem sido conferida à conversação realizada em situações cotidianas e aos modos como os cidadãos constituem seus contextos rotineiros de reflexão e discussão sobre problemas públicos (ELIASOPH, 1997; MANSBRIDGE, 1999; MOY; GASTIL, 2006; EVELAND; MOREY; HUTCHENS, 2011). Eles também salientam que a conversação cotidiana pode trazer contribuições para a deliberação ao melhorar formas de pensar, formular verbalmente, interpretar, argumentar e agir sobre questões políticas que afetam diretamente a vida das pessoas. Entretanto, não é profícuo assumir uma distinção hierárquica entre, de um lado, conversações fluidas, pouco estruturadas e de "baixa politicidade" e, de outro, processos deliberativos fortemente argumentativos, politizados e normativamente organizados. Além disso, não existe necessariamente uma relação de complementariedade entre conversações e processos deliberativos. As esferas que compõem um processo deliberativo ampliado (distendido no tempo e abrangendo diferentes arenas de discussão e conversação) podem se conectar em vários momentos, mas isso nem sempre implica que elas encontram modos satisfatórios de articulação e trânsito comunicativo.

Argumentamos que não se deve relacionar deliberação e conversação a partir do princípio de que a conversação precisa se adequar aos princípios normativos da deliberação para ser válida. A conversação e suas contribuições para a construção de sujeitos e modos de 
agência politicamente autônomos precisam, primeiro, ser avaliadas em si mesmas, sem a necessidade de tecer comparações entre seu modo de operar e os princípios normativos que sustentam a deliberação (racionalidade, publicidade, inclusividade, igualdade, publicidade, reciprocidade e reflexibilidade).

Apesar de alguns autores (MANSBRIDGE, 1999; STROMER-GALEY, 2005) apontarem que conversações políticas informais são capazes de se orientar de acordo com princípios deliberativos, como a consideração racional de pontos de vista, a reciprocidade, a revisão de argumentos, a explicitação de premissas e a justificação recíproca baseada em razões publicamente aceitáveis (Conover e Searing, 2005), a dificuldade de implementação desse tipo de cenário leva a crer que esse enquadramento deliberativo das conversações políticas pode conduzir a expectativas pouco realistas sobre o modo como a conversação funciona propriamente.

Por isso, o enfoque analítico das conversações pode ser mais interessante se procurar revelar como os conflitos, dissensos e discordâncias são trabalhados na interação (EVELAND; MOREY; HUTCHENS, 2011).

Sob esse viés, as implicações que conversações e deliberações possuem umas sobre as outras devem ser apreendidas com cautela, considerando interseções criadas a partir de situações e acontecimentos específicos e não generalizáveis.
É a partir dessa reflexão que buscamos pensar a conversação, nas seções seguintes, como uma forma de ação política (2) com especial atenção à produção de relatos de si (3).

\section{A conversa como elemento político}

Com o evidente risco de se partir de um truísmo, é possível observar que a conversação é um dos pontos de evidência tangível da constituição da vida social. De saída, essa afirmação sugere um ponto de vista especificamente comunicacional para a observação das relações cotidianas que, embora seja aqui assumido, não será problematizado - remete-se à leitura para L. C. Martino (2007) ou Signates (2011).

As interações discursivas cotidianas explicitam de maneira particular as intenções de erigir cenas de interpelação recíproca, nas quais o discurso verbal, mais do que qualquer outro, apresenta-se como um modo de endereçamento à alteridade que pode ser deliberadamente ignorado, mas dificilmente passa despercebido. Enquanto outros modos de comunicação, dentro do vasto espectro dos códigos semióticos humanos e não humanos, podem efetivamente estabelecer um laço, essa possibilidade depende de uma atenção prévia dispensada pelo interlocutor potencial, que pode não estar alerta para a presença convocatória desses códigos.

No caso da interação verbal, a presença do outro torna-se registrada, identificada, desejada: 0 endereçar de um discurso à alteridade 
transforma-a imediatamente em uma presença. 0 que acontece em seguida depende dos vetores de poder, reconhecimento e possibilidade de interação entre ambos na dobra das assimetrias sociais existentes entre si. Porém, a demarcação da presença faz com que o outro seja, ao menos, visto. Exceto em situações extremas, nas quais o outro é destituído de seu reconhecimento como humano, a convocação discursiva assume a perspectiva de uma humanidade do outro com o qual se interage, ainda que de maneira negativa.

0 discurso endereçado à alteridade não apenas a reconhece como presença, mas a chama para a interação de forma inequívoca - ao menos do lado do proferidor: evidentemente equívocos, etimologicamente a "voz igual" referindo-se à ambiguidade latente em algo que é parecido sem ser idêntico, podem existir - para a interação que se desenrolará como perspectiva de algum tipo de confluência discursiva.

Certamente, outras linguagens, como a visual, a gestual ou a sonora, dispõem de uma similar capacidade convocatória; no entanto, é a precisão do discurso verbal, com todas as suas limitações, o elemento que prevê a possibilidade de uma interação inteligível nas minúcias de um código elaborado na verbalização, entendida como característica comum dos participantes do tipo de interação mencionado aqui.

Por certo, nem todas as interações comunicacionais da vida cotidiana podem ser tratadas como relevantes para 0 debate público racional. Muitos conflitos potenciais encontramse dissolvidos no curso de uma conversação em que as frases e as ideias se sucedem sem serem postas em conexão. Contudo, o caráter imprevisível e desordenado da palavra cotidiana não impede que conversações se politizem, dando origem a discussões políticas informais passíveis ou não de se orientarem de acordo com os princípios deliberativos, tais como a consideração racional de pontos de vista, a revisão de argumentos, a explicitação de premissas e a justificação recíproca baseada em razões publicamente aceitáveis.

Assim, há momentos em que os participantes passam não só a expressar publicamente suas opiniões sobre um dado tema político, mas, também, a defendê-las e a revisá-las diante do questionamento alheio. Uma das formas de configuração do processo de politização da conversação cívica é aquela que permite uma passagem de um nível de interação caracterizado por uma comunicação mais intuitiva, para um nível de interação discursiva no qual os cidadãos passam a discutir sobre questões de interesse público, a construir preferências, a refletir sobre as próprias necessidades, considerando e promovendo razões capazes de ampliar o que é entendido como o bem comum.

Maia et al. (2017), em um estudo sobre a conversação a respeito da redução da maioridade penal, indicam também a aproximação da 
alteridade no âmbito da comunicação informal - verificada, no estudo em questão, a partir da experiência relatada em grupos focais. A pesquisa estudou a apropriação e elaboração de discursos em circulação na mídia pelos participantes, mostrando como a existência de posições opostas era um ponto de convocação para a percepção e reconhecimento da diferença - ponto explorado adiante.

Destacamos, nesse segundo processo, a produção de contranarrativas; a explicitação de perspectivas latentes; a iniciativa de assumir os riscos impostos pelo debate; a existência de momentos de tensão entre os interlocutores; a exposição de testemunhos e experiências de vida que podem levar os outros participantes a se reconhecerem e a se engajarem no debate; 0 exercício de pensar sob o ponto de vista do outro, exercendo o respeito mútuo e a reciprocidade (MARQUES, 2007).

Mas nem toda politização pode ser mensurada ou qualificada a partir desses princípios. Há processos de politização que se configuram como experimentações e lutas em torno de linguagens, formas de enunciação e expressão, configuração de mundos e modos de ser e existir que a ordem vigente não alcança e não compreende.

A essa etapa segue-se imediatamente 0 reconhecimento do escopo da conversação nos modelos de interação possíveis na prática conversacional: estamos aí próximos ao domínio de uma pragmática das trocas enunciativas, nas quais os interlocutores transformam suas considerações em ações práticas - 0 ato da fala, visto não como uma referência oblíqua a elementos externos (MONTGOMERY, 1998), mas como ações em si dentro das quais se estabelece uma movimentação de ordem prática entre quem conversa - e aqui os ecos de Wittgenstein (1998) não se deixam escapar: a pragmática da linguagem, em sua dimensão como uma ação na direção do outro, reveste-se por isso mesmo de um elemento político no âmbito de uma razão prática que se insere no cotidiano.

A conversação, sob este ponto de vista, adiciona ao seu aspecto referencial uma dimensão de interação prática da qual deriva um potencial político implícito em qualquer interação: 0 endereçamento ao outro já é, em si, uma instância do político, e não seria demais sugerir que a presença da alteridade à qual o discurso é endereçado, por seu turno, também decorre da possibilidade política de reconhecimento desse outro - e, como aponta Gutierrez (2006), de sua classificação dentro de um sistema lógico, 0 qual lhe designará um lugar específico dentro do conjunto de representações, eivada de hierarquias, constitutivo da vida social.

Por esse aspecto, a conversação cotidiana, mesmo em sua dimensão mais simples, não parece se apresentar como ociosa em termos políticos: ao contrário, a seleção temática, a escolha lexical, a atualização de um tipo de registro linguístico em detrimento de outros, a 
consideração do interlocutor e os pressupostos de cada proferimento se constituem em um dispositivo conversacional responsável por uma interação que, para além de qualquer caráter referencial ou informativo, reveste-se quase que imediatamente de um caráter político. Isso é reforçado na medida em que a conversação, porquanto faça referência a eventos externos ao espaço específico da troca linguística - exceção feita aos procedimentos metalinguísticos presentes, evidentemente, como potencial em todo discurso- tende a construir uma narrativa a respeito da realidade e convocar 0 interlocutor a aceitar essa narrativa como representação fiel; a discordância, neste caso, significa também uma disputa política no sentido da atribuição de significados específicos a um significante em constante flutuação, sem um significado prévio senão aqueles cristalizados no uso e nas práticas.

Dessa maneira, mesmo a conversação aparentemente menos inclinada a uma temática "política", no sentido estrito do termo, ganha um aspecto político na medida em que estão em jogo, em qualquer discussão, a atribuição e o reconhecimento mútuo de significados em relação a um significante que é objeto dos proferimentos. Essa perspectiva de disputa na atribuição de um significado ao real é um dos elementos constituintes de qualquer discussão: a ambivalência do real manifesta-se em suas apropriações discursivas, apresentadas nos proferimentos dos interlocutores.

\section{A política nas narrativas de si}

Certamente, como constatado, as interações postas em prática pela conversação efetivamente apresentam como problema específico a desorganização argumentativa: a ausência de regras indica a inexistência de qualquer direcionamento para algum tipo de busca por justificação recíproca ou mesmo de consenso mínimo sobre o que está sendo discutido. Ao mesmo tempo, porém, isso transforma as conversações cotidianas em brechas nas quais o sentido do político é alcançado e (re)criado em outros aspectos, derivados da espontaneidade das relações e na constituição de relatos e narrativas a respeito de si e do mundo que trazem inscritas nelas mesmas as concepções, as práticas, as condições e, de maneira geral, as marcas das condições de sua elaboração.

Se 0 elemento de argumentação propriamente racional e normativo não ocupa uma posição central no ato conversacional cotidiano, é possível observar que, em seu lugar, outros tipos de proferimentos são utilizados como suporte às posições apresentadas. 0 apelo ao elemento pessoal, à narrativa biográfica ou 0 recurso a argumentos vagos, se, por um lado, desafiariam a constituição de uma argumentação normatizada - na retórica medieval, os exempla não eram considerados 0 elemento mais digno dentro de uma disputatio, sendo preferidas as demonstrações lógicas e o recurso à autoridade de autores consagrados - por outro lado, garantem a continuidade de uma conversação. 
A própria condição, em geral, na qual se desenrolam conversas cotidianas, não prevê a possibilidade de demonstrações de caráter lógico mais profundo ou com o recurso à autoridade prévia - em uma conversação trivial, um acontecimento desse tipo beiraria 0 anedótico, sendo potencialmente um gerador de mal-estar no âmbito da interlocução: ninguém, em uma discussão familiar, evocaria a autoridade de um filósofo para decidir, por exemplo, qual será 0 passeio do final de semana ou qual tipo de pizza será encomendado.

0 recurso, nesse caso, é vinculado a uma condição de pessoalidade que deixa de lado, a princípio, toda e qualquer vinculação política. No entanto, se a trivialidade do exemplo poderia de imediato sugerir isso, observe-se que não se está falando de relações presumidamente harmoniosas em nenhuma esfera, mas no estabelecimento de determinadas condições de fala que explicitam a presença de poderes, vozes com mais ou menos força, elementos de ação e transição específicos que regulam o fluxo de qualquer conversação. A ausência de uma normatização prévia se canaliza para a potência dos vínculos afetivos: a conversação entra, nesse caso, no domínio dos afetos, fazendo convergir 0 espectro das paixões, das vivências, das situações de vida e dos poderes nelas implicados. 0 caráter afetivo da conversação, evidentemente, não se opõe ao racional, senão em uma relação de complementaridade.
Uma experiência dissensual, a nosso ver, está associada às potências de criação e recriação de enunciados e formas de enunciação a partir das quais o sujeito se constrói conflitiva e narrativamente. Essa perspectiva poderia imediatamente levantar 0 questionamento a respeito das possibilidades práticas do estabelecimento de qualquer tipo de caráter político na conversação, uma vez que esse elemento "aleatório" ou de "devaneio" pode se apresentar como 0 antípoda da atenção necessária a um tipo de conversação que se apresente como política. Entretanto, isso não parece invalidar de antemão as possibilidades de uma interação de caráter político: na vida social, o político permeia 0 tecido das conversações referentes aos vários âmbitos do cotidiano, direcionando preferencialmente para os temas chamados de "interesse público", mas cada vez mais margeando também os espaços da vida privada, na medida em que suas condições de possibilidade não escapam às linhas de força contingentes da ação política. Não por acaso, autoras e autores vinculados às chamadas "políticas de identidade" (YOUNG, 1997, 2000) não deixam de apontar para a politização do privado como característica da política contemporânea: abre-se uma brecha para pensar a conversação política para além da normatização, mas como uma atividade latente em todo e qualquer tipo de interação na qual pontos de vista referentes ao cotidiano são explicitados e, a partir de uma série de proferimentos, são propostos para apreciação e resposta de um interlocutor. 
A produção de relatos de si revela uma clara intenção de assumir o controle da própria vida, de tornar-se sujeito de si mesmo por meio do trabalho de reinvenção da própria subjetividade possibilitada pelo relato de si. Trata-se de se tornar autor do próprio script, a partir de uma relação específica do indivíduo consigo mesmo.

Foucault $(1995,2004)$ considera como técnicas de si os procedimentos por meio dos quais um indivíduo se "apropria de si", transformando-se em sujeito de suas próprias práticas e construindo a si mesmo a partir de uma perspectiva ética que busca distanciar-se das regulações e normatividades do Estado.

A prática da escrita de si necessita do comprometimento do sujeito com a veracidade e verdade de suas considerações acerca de trajetórias, conflitos, frustrações e vitórias, utilizando a escrita como ferramenta política. Nesse sentido, a escrita de si, 0 "narrar-se" e 0 relatar a si mesmo (BUTLER, 2015; RAGO, 2013) estão implicados na construção da subjetividade que mantém sua abertura e 0 caráter processual do ser (seres em devir). Revela um trabalho ético de construção subjetiva na experiência dissensual da escrita e do atual registro online, por exemplo, o qual permite ao indivíduo examinar criticamente sua condição em relação aos discursos normalizadores, em busca da afirmação de novos modos de expressão subjetiva, política e social.
No espaço de uma interação cotidiana, o resgate narrativo de situações vividas por si mesmo ou por outrem constitui uma força considerável de argumentação. Substituindo, ou completando, qualquer outra demonstração de caráter lógicoracional, o traço biográfico reveste-se de especial força na construção de uma argumentação: história contada a respeito da vida, a narrativa biográfica atualiza uma situação tomada ou tomável - como exemplar do argumento defendido. Dotada de um considerável efeito de real decorrente, de maneira quase paradoxal, da presença do narrador como testemunho e garantia de veracidade, a narrativa biográfica, utilizada como exemplo, ganha espaço nas trocas conversacionais como um elemento tendencialmente apto a assegurar não apenas a relevância, mas, sobretudo, a veracidade do que é narrado - "veracidade", neste caso, não em termos epistemológicos, mas antes narrativos: a plausibilidade do discurso se afirma diante do testemunho, peça jurídica aqui transformada em garantia do que se está dizendo.

Há, porém, novamente uma clivagem neste aspecto. Trata-se da possibilidade e das condições de contar a própria história. Se, como afirma Couldry (2010), o direito à voz é um dos bens distribuídos em condições mais desiguais no cotidiano, é imperioso observar que a possibilidade de narrar a si mesmo é igualmente mal distribuída também na história de grupos sociais. Talvez não seja por acaso que Spivak (2010) questione, em seu texto sobre 
subalternidade, as possibilidades do "subalterno falar": 0 direito a falar de si mesmo como produção afirmativa de um "eu" definido em seu protagonismo - e não como aspecto capturado na reflexividade do discurso de outro - é uma das formas de estabelecimento e identificação das fronteiras hierárquicas presentes na distribuição social da voz. 0 reconhecimento do direito à voz não é dado, mas conquistado junto com 0 direito à presença no espaço público: assim, as questões das políticas de identidade parecem convergir com a perspectiva de um direito à voz de indivíduos que, ao falarem de si, falam de seus grupos, de suas origens e reforçam seus vínculos comunitários.

0 ato de falar de si mesmo, neste aspecto, borra algumas das fronteiras do pessoal e do público em prol do político: a narrativa biográfica não está baseada no agrupamento aleatório de tomadas de decisão estritamente pessoal, na mesma medida em que não se apoia em um determinismo social que engessaria toda e qualquer possibilidade de mudança: ao contrário, é por conta de uma interação entre essas duas condições que 0 social se apresenta, em termos da experiência, como uma indeterminação condicionada, isto é, como uma série de elementos que, embora escapem de qualquer perspectiva determinista o que, epistemologicamente, eliminaria qualquer iniciativa de apreensão - por outro lado, também não escapa aos elementos condicionantes da ação. É nessa articulação tensional entre condições e possibilidades que se vislumbra 0 direito à fala autônoma como uma das fontes de participação política.

A fala ou relato de si estabelece uma narrativa afetiva de identidade, na qual o "eu" é estabelecido como protagonista a partir do qual se realizará a apropriação reflexiva da alteridade e do mundo. Daí a diferença política básica entre narrar e ser narrado por outrem: a perspectiva de narrar, a centralidade, ainda que momentânea, de quem conta a própria história desloca as linhas de força constitutivas de qualquer narrativa para 0 sujeito narrador, em condição tornada excêntrica em relação às narrativas dominantes dentro de uma sociedade. É por conta disso que a condição de narrar a própria vida, contar a própria história transformada em uma ipseidade - em oposição às normatizações narrativas que 0 constituem como uma alteridade em uma história que igualmente não é a sua - parece ser uma condição essencial da vida política que se desenha nas tramas conversacionais do cotidiano.

Dessa maneira, 0 ato de falar de si mesmo em uma conversa cotidiana não parece ser indício de banalidade ou da falta de argumentos melhores, mas, antes, uma demarcação de posições narrativas decorrentes da possibilidade de, ao falar de si mesmo, falar também de seus grupos, de suas comunidades, de suas histórias que, embora certamente vividas em um aspecto subjetivo, não deixam de trazer em si condições objetivas - e subjetivadas - de sua ocorrência. 


\section{Considerações finais}

Vários autores revelam que a maior parte de nossas interações e conversações cotidianas ocorre em contextos privados. Por um lado, nesses contextos, indivíduos, grupos e coletividades cultural e materialmente subordinados aprendem a tomar a injustiça como inquestionável, a experimentá-la como algo que faz parte, naturalmente, do senso comum. Por outro lado, contudo, essas esferas configuram o principal contexto em que esses públicos trocam impressões e produzem narrativas de si que desafiam os discursos públicos amplamente aceitos (SCOTT, 1990; HERBST, 1996).

0 argumento de que âmbitos privados de conversação proporcionam poucas oportunidades para desenvolvermos confiança nas pessoas que são diferentes de nós e que pensam de forma distinta (CONOVER, SEARING, 2005; MOY, GASTIL, 2008) ainda é muito forte entre os autores. Passamos mais tempo com amigos, familiares e colegas que têm maior probabilidade de apresentarem pontos de vista semelhantes aos nossos. Sendo assim, raramente, as pessoas interagem com outras que pensam de maneira dissonante, que sustentam pontos de vista contrários e que possuem um background distinto.

Os fluxos conversacionais desorganizados, desfocados e abertos das trocas constituídas nos grupos abrigam uma dinâmica rica em mecanismos capazes de modelar discussões políticas marcadas pela pluralização dos pontos de vista, de mundos possíveis e modos de aparecer em público que envolvem identificação e desidentificação, revelar e esconder, classificar e desclassificar, mobilizando repertórios e renovando-os, criando enunciados que transbordam léxicos muito bem definidos e delimitados. Mas essas operações de experimentação e criação também sofrem com a necessidade de articular a astúcia/espontaneidade e inovação com a institucionalização e a norma.

No âmbito da interface traçada entre a conversação e a deliberação, ainda é privilegiada uma visão que caracteriza a conversação como "prima pobre" da deliberação. A conversação sobre temas e assuntos publicamente relevantes, para contribuir com processos deliberativos ampliados, requer que os parceiros dialógicos construam seus pontos de vista e sejam capazes de explicá-los e defendê-los diante de indagações alheias. Essa é uma tarefa particularmente difícil por dois motivos principais: a) estudos ressaltam que a discussão política informal é pouco propícia à expressão de desacordos (DUCHESNE e HAEGEL, 2004; CONOVER et al., 2002); b) pesquisas empíricas sobre conversações e discussões políticas raramente são realizadas em contextos rotineiros de circulação e vivência dos cidadãos comuns, uma vez que a maior parte delas concentra-se em fóruns deliberativos formais, reuniões e assembleias locais.

Nos espaços informais, as pessoas estão mais propensas a se engajarem em interações 
complementares nas quais suas experiências, convertidas em pequenas narrativas e testemunhos, tendem a se aproximar da fala do outro, ponto observado anteriormente por Maia et al. (2017).

Na teoria deliberativa, são principalmente 0 conflito e o desacordo moral, e as estratégias de sua explicitação que revelam o potencial das conversações cotidianas informais para a construção de formas diversas de participação política (WYATT, KATZ e KIM, 1999, 2000; BENNETT, FLICKINGER e RHINE, 2000; WEST e GASTIL, 2004). Seria nesse sentido que, com o passar do tempo, a conversação cívica pode contribuir para o processo democrático através do aprimoramento e da sofisticação dos julgamentos públicos que, por sua vez, influenciam processos de construção de políticas públicas (MOY e GASTIL, 2006).

Alguns pesquisadores não têm poupado esforços para estabelecer contextos e criar procedimentos capazes de revelar os momentos em que a conversação fluida e dispersa do cotidiano dá origem a uma discussão pública em que prevaleçam: posições conflitantes, apresentação de argumentos claros e lógicos, esclarecimento e revisão de premissas, respeito mútuo e esclarecimento recíproco entre as várias opiniões em disputa (MUTZ e MONDAK, 2006; DUCHESNE e HAEGEL, 2004).

Em uma outra perspectiva, a conversação tem sido associada à produção reflexiva de narrativas de si, capazes de promover a invenção da cena de interlocução na qual se inscreve a palavra do sujeito falante, e na qual esse próprio sujeito se constitui ao se pronunciar em primeira pessoa e de identificar sua afirmação com a reconfiguração de um universo de possibilidades e potências.

A narrativa biográfica faz da tarefa de interpretação da realidade um ato no qual explicações racionais e justificações subjetivas convergem para 0 tecido da trama textual: acontecimentos não são necessariamente apreendidos em sua dimensão social e histórica, mas como parte de uma história de vida na qual outras linhas também se cruzam. Os estudos relacionados à história oral há muito indicam essa possibilidade de entrecruzamento, alertando para a dimensão de relações afetivas e racionais, objetivas e subjetivas presentes em qualquer relato.

Em ponto menor, isso parece acontecer com igual força nas interações conversacionais cotidianas: 0 recurso ao elemento vivido como argumento não separa, evidentemente, fato de apreensão subjetiva do fato. Sua força, aliás, parece residir justamente nessa ausência de separação provocada pelo vínculo do afeto: é nesse momento que se dá a subjetivação narrativa de uma situação, que pode ser interpretada pelo falante de acordo com os discursos nos quais se insere - ou é inserido. 0 elemento biográfico e narrativo, neste particular, se torna um espaço particularmente privilegiado de formação das interações cotidianas, mas apenas na medida em que essas vozes possam ser 
ouvidas em seu protagonismo: o pessoal se torna político com a condição de que esse pessoal tenha condições de afirmar sua dimensão como sujeito de um discurso a respeito de si mesmo, o qual não desapareça no emaranhado de outros discursos que permeiam o tecido social.

\section{Referências}

ALDÉ, Alessandra. A construção da política: democracia, cidadania e meios de comunicação de massa.Rio de Janeiro: FGV, 2004.

BENHABIB, Seyla. (ed.). Democracy and Difference - contesting the boundaries of the political. Princeton: Princeton University Press, 1996.

BENNETT, Stephen; FLICKINGER, Richard; RHINE, Staci. Political Talk over here, over there, over time.

British Journal of political Science, v. 30, p. 99-119, 2000 .

BOHMAN, James. Public Deliberation: pluralism, complexity, and democracy. Massachusetts: Mit Press, 1996.

Political Communication and the epistemic value of diversity: deliberation and legitimation in media societies. Communication Theory, v.17, p. 348-355, 2007.

BURKHALTER, Stephanie; GASTIL, John; KELSHAW, Todd. A conceptual definition and theoretical model of public deliberation in small face-to-face groups.

Communication Theory, v.12, n.4, p. 398-422, nov. 2002, BUTLER, Judith. Gender trouble. Londres: Routledge, 2008.

Relatar a si mesmo.Belo Horizonte: Autêntica, 2015.

CALHOUN, Craig (ed.). Habermas and the Public Sphere. Cambridge: MIT Press,1992.
CONOVER, Pamela; SEARING, Donald; CREWE, Ivor. The Deliberative Potential of Political Discussion. British Journal of Political Science, v.32, p.21-62, 2002. CONOVER, Pamela; SEARING, Donald. Studying 'Everyday Political Talk' in the Deliberative System. Acta Politica, v. 40, p. 269-283, 2005.

COOKE, Maeve. Five arguments for Deliberative Democracy. Political Studies, v.48, p. 947-969, 2000.

COULDRY, Nick. Why voice matters. Londres: Sage, 2010. DAHLBERG, Lincoln. The internet and democratic discourse: exploring the prospects of online deliberative forums extending the public sphere. Information,

Communication \& Society, v.4, n.4, p. 615-633, 2001.

DAHLGREN, Peter. The Internet, Public Spheres, and Political Communication: dispersion and deliberation. Political Communication, n.22, p.147-162, 2005. In search of talkative public: media, deliberative democracy, and civic culture, Javnost the public, v.9, n.3, p.5-26, 2002.

Media and political engagement. New

York: Cambridge University Press, 2009.

DUCHESNE, Sophie; HAEGEL, Florence. La polititisation des discussions, au croisement des logiques de specialisation et de conflictualisation. Revue française de science politique, v. 54, n. 6, p. 877-909, dec. 2004b. Avoiding or Accepting conflict in Public Talk. British Journal of Political Science, v. 37, p.122,2006 .

ELIASOPH, Nina. Close to home: the work of avoiding politics. Theory and Society, v.26, p. 605-647, 1997. Is conversation the soul of democracy? America's Child-Centered civic life, a civic culture that defies all theories of civil society. Paper presented at American Political Development Workshop, University of Wisconsin, 2000. Disponível em: www. 
polisci.wisc.edu/ coleman/apd/eliasoph.pdf Acesso em: 28/07/06.

Making a Fragile Public: a talk-centered

study of citizenship and power. Sociological Theory, v. 14, n. 3, p. 262-89, 1996.

What if good citizens etiquette requires silencing political conversation in everyday life? Notes from the field. Paper presented at Conference on "The Transformation of Civic life", Middle Tennessee State University, November, 1999.

EVELAND, William; MOREY, Alyssa; HUTCHENS, Myiah. Beyond Deliberation: New Directions for the Study of Informal Political Conversation from a Communication Perspective. Journal of Communication, n. 61, p. 1082-1103, 2011.

FEARON, James D. Deliberation as Discussion. In: ELSTER, Jon (ed.). Deliberative Democracy. Cambridge: Cambridge University Press, p. 44-68, 1998.

FOUCAULT, Michel. Genealogia da Ética, Sexualidade, Subjetividade. Rio de Janeiro: Forense, 2004.

História da Sexualidade. Rio de

Janeiro: Graal, 1995.

GAMSON, William. Talking Politics. Cambridge:

Cambridge University Press, 1992.

GAMSON, William.; MODIGLIANI, A. Media discourse and Public Opinion on Nuclear Power; a constructionist approach. American Journal of Sociology, v. 95, n.1, p. $38-107,1989$.

GASTIL, John. Political Communication and deliberation. Londres: Sage Publication, 2008.

GRAHAM, Todd. Needles in a haystack: a new approach for identifying and assessing political talk in nonpolitical discussion forums. Javnost-the public, Ljubljana, v.15, n. 2, p. 17-36. 2008.

GRAHAM, Todd; JACKSON, Daniel; WRIGHT, Scott. We need to get together and make ourselves heard: everyday online spaces as incubators of political action.

Information, Communication \& Society, v.19, n.10, p.1373-1389, 2015.

GUTIERREZ, A. G. Desclasificados. Barcelona: Anthropos, 2006.

GUTMANN, Amy \& THOMPSON, Dennis. Democratic Disagreement. In: MACED0, Stephen (ed.). Deliberative Politics: essays on democracy and disagreement. 0xford: Oxford University Press, p. 243-279, 1999.

HABERMAS, Jürgen. Direito e Democracia. Rio de Janeiro: Tempo Brasileiro, 1997.

Theorie of Communicative Action. v .2.

Nova York: Beacon Press, 1987.

HERBST, Susan. Public Expression Outside the Mainstream. The Annals of the American Academy of Political and Social Science, v. 546, p.120-131, 1996.

KIM, J.; KIM, E. J. Theorizing dialogic deliberation: everyday political talk as communicative action and dialogue, Communication Theory, v. 18, p. 51-70, 2008.

KIM, J.; WYATT, R.; KATZ, E. News, Talk, Opinion, Participation: the part played by conversation in deliberative democracy. Political Communication, v. 16, p.361-385, 1999 .

MAIA, Rousiley Celi Moreira e MARQUES, Ângela Cristina Salgueiro. Cultural Production and public debate on 'sexual other': the struggle for recognition in Brazil. Intersections - The Journal of Global Communications \& Culture, Athens/ Greece, v.2, issues 3-4, p. 59-68, 2002.

MAIA, Rousiley Celi Moreira. Dos Dilemas da Visibilidade Midiática para a Deliberação Pública. In: LEMOS, André et al. (orgs.). Livro da XII Compós: Mídia.br. Porto Alegre : Sulina, 2004.

MAIA, Rousiley Celi Moreira et alli. Conversação e deliberação sobre questões sensíveis: um estudo sobre o uso das razões que circulam nos media. Galáxia, n. 34, p. 55-72. jan./abr., 2017. 
MANSBRIDGE, Jane. Everyday Talk in Deliberative System. In: MACEDO, Stephen (ed.).Deliberative Politics: essays on democracy and disagreement. Oxford: Oxford University Press, p. 211-239, 1999.

MARQUES, Ângela. Aspectos teórico-metodológicos do processo comunicativo de deliberação online. Revista

Brasileira de Ciência Política, v. 6, p. 19-40, 2011.

MARQUES, Ângela Cristina Salgueiro e ROCHA, Simone Maria. A política a partir das margens: a produção discursiva sobre o Bolsa-Família em grupos de discussão. Famecos, n. 32, p.105-117, abr. 2007.

MARQUES, Ângela e MAIA, Rousiley. Dimensões da Autonomia no combate à pobreza: o programa BolsaFamília sob a perspectiva das beneficiárias. Serviço Social e Sociedade, v. 92, p. 58-85, nov. 2007a. . A conversação sobre temas políticos em contextos comunicativos do cotidiano. Politica \& Sociedade, v. 7, p. 143-175, 2008.

Everyday Conversation in the

Deliberative Process: An Analysis of Communicative Exchanges in Discussion Groups and Their Contributions to Civic and Political Socialization.

Journal of Communication, v. 60, p. 611-635, 2010.

MARTINO, L. M; MARQUES, A. C. S. A ética da comunicação a partir da abordagem dos conceitos de interesse e uso da linguagem. Galáxia, São Paulo, v. 23, p. 139-152, 2012.

MARTINO, L. M. S. A potência da alteridade nas mídias digitais. Conferência de Abertura do VIII EcoMig. Belo Horizonte: FAFICH-UFMG, out. 2015. Comunicação e Identidade. São Paulo: Paulus, 2010.

McLEOD, Jack ; SCHEUFELE, Dietram ; MOY, Patricia ; HOROWITZ, Edward ; HOLBERT, R. ; ZHANG, Weiwu; ZUBRIC, Stephen; ZUBRIC, Jessica. Understanding Deliberation: the effects of discussion networks on participation in a public forum. Communication
Research, v. 26, n. 6, p.743-774, dec. 1999.

MONTGOMERY, C. Introduction to Language and

Society. Londres: Routledge, 1998.

MOY, Patricia; GASTIL, John. Predicting deliberative conversation: The impact of discussion networks, media use, and political cognitions. Political Communication, v. 23, n. 4, p. 443-460, 2006.

MUTZ, Diana e MONDAK, Jeffery. The Workplace as a context for crosscutting political discourse. Journal of Politics, v. 68, p.140-155, 2006.

NORRIS, Pippa. A Virtuous Circle: Political

Communication in Postindustrial Societies.

Cambridge: Cambridge University Press, 2000.

P0RT0, Mauro. Enquadramentos da mídia e

Política. In: RUBIN, Antonio Albino Canelas (org.).

Comunicação e Política: conceitos e abordagens.

Salvador: Edufba/Unesp, p.74-104, 2004.

Idéias e fatos: telenovelas e imaginário político no Brasil, Cultura Vozes, n. 6, p. 83-93, nov./ dez., 1994.

RAG0, Margareth. A aventura de contar-se. Campinas: Ed. Unicamp, 2013.

SANDERS, Lynn. Against Deliberation. Political Theory, v. 25, p. 347-76, 1997.

SCHEIN, Virginia E. Working from the margins: voices of mothers in poverty. London: Cornell University Press, 1995.

SCHEUFELE, B. Framing-effects approach: A theoretical and methodological critique.

Communications, v. 29, p. 401-428, 2004.

SCOTT, James. Domination and the Arts of

Resistance - Hiddens Transcripts. New Haven: Yale University Press, 1990.

SEARING, Donald; CONOVER, Pamela; CREWE, Ivor; SOLT, Fred. "Studying Everyday Talk in the Deliberative System: does democratic discussion make 
better citizens?". Paper apresentado à Conferência Empirical Approaches to Deliberative Politics, promovida pelo European University Institute/Swiss Chair e realizada em Firenze, nos dias 22 e 23 de Maio de 2004.

SPIVAK, G. C. Pode o subalterno falar? Belo

Horizonte: Editora da UFMG, 2010.

WEST, Mark; GASTIL, John. "Deliberation at the margins: participant accounts of face-to-face public deliberation at the 1999-2000 World trade protests in Seattle and Prague". Qualitative Research Reports in Communication, v. 5, p. 1-7, 2004.

WITTGENSTEIN, L. Investigações Filosóficas.

Petrópolis: Vozes, 1998.

WRIGHT, S. From "Third place" to "third space": everyday political talk in non-political online spaces. Javnost, v.19, n.3, 2012.

YOUNG, Iris. Difference as a Resource for Democratic Communication. In: BOHMAN, J. \& REHG, W.

Deliberative Democracy. Cambridge: MIT Press, $p$. 383-406. 1997.

Inclusion and Democracy. Oxford:

Oxford University Press, 2000. 


\section{The politization of everyday talk and its relations with the deliberative process}

\section{Abstract}

Deliberative tradition in Political Studies has been regarding civic conversation as one of the fundaments of democracy. However, less attention has been paid for casual conversations, seen as trivial and therefore unsuitable for political interaction. This paper highlights the role of everyday talk in the constitution of citizenship, stressing the political elements that underline every talk. The argument goes threefold: (1) it states some differences between 'deliberation' and 'conversation'; (b) it argues that every talk is political talk; (c) by underlining the place of self narratives as the political element of everyday talk. From this, we advance the hypothesis that daily conversations, far from any triviality, are presented as basic processes for the formation of a political public opinion.

\section{Keywords}

Democracy. Deliberation. Identity. Politics.

Communication.

\section{La politización de las conversas y sus relaciones con el proceso deliberativo}

\section{Resumen}

La tradición deliberativa en Comunicación y Política a menudo pone en relieve la conversación cívica como una de las bases de la democracia. Sin embargo, se da menos atención a la charla, descartada desde un punto de vista político. Este texto busca rescatar el sentido político de lo trivial destacando las posibilidades de politización del hablar cotidiana. El argumento se desarrolla en tres etapas: (1) la diferenciación de la resolución de la conversación, (2) destacando los aspectos políticos de este último (3), con especial referencia a la producción de narrativas de sí mismos en el proceso. De esto, se avanza la hipótesis de que las conversaciones diarias, distantes de cualquier trivialidad, si presentan como procesos básicos para la formación de una opinión pública política.

\section{Palabras clave}

Democracia. Deliberación. Identidad. Politica. Comunicación. 


\section{Expediente}

A revista E-Compós é a publicação científica em formato eletrônico da Associação Nacional dos Programas de Pós-Graduação em Comunicação (Compós). Lançada em 2004, tem como principal finalidade difundir a produção acadêmica de pesquisadores da área de Comunicação, inseridos em instituições do Brasil e do exterior.

\section{E-COMPÓS I www.e-compos.org.br I E-ISSN 1808-2599}

Revista da Associação Nacional dos Programas de Pós-Graduação em Comunicação.

Brasília, v.20, n.1, jan./abr. 2017.

A identificação das edições, a partir de 2008, passa a ser volume anual com três números.

Indexada por Latindex I www.latindex.unam.mx

\section{CONSELHO EDITORIAL}

Alda Cristina Silva da Costa, Universidade Federal do Pará, Brasil Alfredo Luiz Paes de Oliveira Suppia, Universidade Estadual de Campinas, Brasil Álvaro Larangeira, Universidade Tuiuti do Paraná, Brasil Ana Carolina D. Escosteguy, Pontifícia Universidade Católica do Rio Grande do Sul, Brasil Ana Regina Barros Rego Leal, Universidade Federal do Piauí, Brasil Ana Carolina Rocha Pessôa Temer, Universidade Federal de Goiás, Brasil Andrea França, Pontifícia Universidade Católica do Rio de Janeiro, Brasil André Luiz Martins Lemos, Universidade Federal da Bahia, Brasil Angela Cristina Salgueiro Marques, Faculdade Cásper Libero, Brasil Ângela Freire Prysthon, Universidade Federal de Pernambuco, Brasil Antonio Carlos Hohlfeldt, Pontifícia Universidade Católica do Rio Grande do Sul, Brasil Arthur Ituassu, Pontifícia Universidade Católica do Rio de Janeiro, Brasil Bruno Campanella, Universidade Federal Fluminense, Brasil Cláudio Novaes Pinto Coelho, Faculdade Cásper Líbero, Brasil Carlos Eduardo Franciscato, Universidade Federal de Sergipe, Brasil Denise Tavares da Silva, Universidade Federal Fluminense, Brasil Eduardo Vicente, Universidade de São Paulo, Brasil Eliza Bachega Casadei, Escola Superior de Propaganda e Marketing - SP, Brasil Elizabeth Nicolau Saad Corrêa, Universidade de São Paulo, Brasil Erick Felinto de Oliveira, Universidade do Estado do Rio de Janeiro, Brasil Erly Vieira Júnior, Universidade Federal do Espirito Santo, Brasil Francisco de Assis, FIAM-FAAM Centro Universitário, Brasil Francisco Elinaldo Teixeira, Universidade Estadual de Campinas, Brasil Frederico de Mello Brandão Tavares, Universidade Federal de Ouro Preto, Brasil Gabriela Reinaldo, Universidade Federal do Ceará, Brasil Gilson Vieira Monteiro, Universidade Federal do Amazonas, Brasil Gustavo Daudt Fischer, Universidade do Vale do Rio dos Sinos, Brasil Igor Sacramento, Fundação Oswaldo Cruz, Brasil Itania Maria Mota Gomes, Universidade Federal da Bahia, Brasil Jiani Adriana Bonin, Universidade do Vale do Rio dos Sinos, Brasil José Afonso da Silva Junior, Universidade Federal de Pernambuco, Brasil
José Luiz Aidar Prado, Pontifícia Universidade Católica de São Paulo, Brasil Juçara Gorski Brittes, Universidade Federal de Ouro Preto, Brasil Laura Loguercio Cánepa, Universidade Anhembi Morumbi, Brasil Liziane Soares Guazina, Universidade de Brasilia, Brasil Luíza Mônica Assis da Silva, Universidade Católica de Brasília, Brasil Maria Ataide Malcher, Universidade Federal do Pará, Brasil Maria Elisabete Antonioli, Escola Superior de Propaganda e Marketing - SP, Brasil Maria das Graças Pinto Coelho, Universidade Federal do Rio Grande do Norte, Brasil Marcel Vieira Barreto Silva, Universidade Federal da Paraíba, Brasil Marcia Tondato, Escola Superior de Propaganda e Marketing, Brasil Marli Santos, Universidade Metodista de São Paulo, Brasil Márcio Souza Gonçalves, Universidade do Estado do Rio de Janeiro, Brasil Mauricio Mario Monteiro, Universidade Anhembi Morumbi, Brasil Mauricio Ribeiro da Silva, Universidade Paulista, Brasil Mauro de Souza Ventura, Universidade Estadual Paulista, Brasil Mayka Castellano, Universidade Federal Fluminense, Brasil Micael Maiolino Herschmann, Universidade Federal do Rio de Janeiro, Brasil Mozahir Salomão Bruck, Pontifícia Universidade Católica de Minas Gerais, Brasil Nísia Martins Rosario, Universidade Federal do Rio Grande do Sul, Brasil Potiguara Mendes Silveira Jr, Universidade Federal de Juiz de Fora, Brasil Raquel Ritter Longhi, Universidade Federal de Santa Catarina, Brasil Regiane Regina Ribeiro, Universidade Federal do Paraná, Brasil Roberto Elísio dos Santos, Universidade Municipal de São Caetano do Sul, Brasil Rodolfo Rorato Londero, Universidade Estadual de Londrina, Brasil Sérgio Luiz Gadini, Universidade Estadual de Ponta Grossa, Brasil Simone Maria Andrade Pereira de Sá, Universidade Federal Fluminense, Brasil Simone Maria Rocha, Universidade Federal de Minas Gerais, Brasil Suzana Reck Miranda, Universidade Federal de São Carlos, Brasil Tarcyanie Cajueiro Santos, Universidade de Sorocaba, Brasil Tatiana Oliveira Siciliano, Pontifícia Universidade Católica do Rio de Janeiro, Brasil Veneza Mayora Ronsini, Universidade Federal de Santa Maria, Brasil

\section{CONSELHO CIENTÍFICO}

Cristiane Freitas Gutfreind, Pontifícia Universidade Católica do Rio Grande do Sul, Brasil Eduardo Morettin, Universidade de São Paulo, Brasil

Felipe Costa Trotta, Universidade Federal Fluminense, Brasil Irene de Araújo Machado, Universidade de São Paulo, Brasil

\section{COMISSÃO EDITORIAL}

Eduardo Antonio de Jesus, Universidade Federal de Minas Gerais, Brasil Marco Antonio Roxo da Silva, Universidade Federal Fluminense, Brasil Osmar Gonçalves dos Reis Filho, Universidade Federal do Ceará, Brasil

\section{CONSULTORES AD HOC}

Kelly C. de Souza Prudencio, Universidade Federal do Paraná, Brasil Francisco P. Jamil A. Marques, Universidade Federal do Paraná, Brasil Tiago Quiroga F. Neto, Universidade de Brasília, Brasil

\section{EQUIPE TÉCNICA}

ASSISTENTE EDITORIAL Márcio Zanetti Negrini REVISÃO DE TEXTOS Press Revisão EDITORAÇÃO ELETRÔNICA Roka Estúdio IMAGEM DE CAPA Silas de Paula

\section{COMPÓS I www.compos.org.br}

Associação Nacional dos Programas de Pós-Graduação em Comunicação

Presidente

Edson Fernando Dalmonte

Programa de Pós-Graduação em Comunicação

e Cultura Contemporânea - UFBA

edsondalmonte@uol.com.br

Vice-presidente

Cristiane Freitas Gutfreind

Programa de Pós-Graduação em Comunicação Social - PUC-RS cristianefreitas@pucrs.br

Secretário-Geral

Rogério Ferraraz

Programa de Pós-Graduação em Comunicação

Universidade Anhembi Morumbi

rogerioferraraz@anhembimorumbi.edu.br

CONTATO I revistaecompos@gmail.com 